\title{
¿Qué significa trabajar? Una aproximación a la visión de los freelance sobre la actividad laboral
}

\author{
What does work mean? An approach to the vision \\ of freelance workers about work activity
}

\author{
doi: http://dx.doi.org/10.32870/ \\ espiral.v23i67.4252
}

\begin{abstract}
Resumen
En este artículo se expone e interpreta la concepción de un grupo de trabajadores independientes sobre el trabajo. Se intenta comprender el significado que ellos dan al hecho de trabajar. Los datos proceden de una investigación en curso en la que se busca conocer el proceso por el cual los profesionales del medio audiovisual se convierten en independientes y la evaluación que hacen de su experiencia como autónomos. Se entrevistó a profundidad a veintiuno de estos y se visitaron blogs y grupos de Facebook en los cuales se exponen percepciones sobre el mundo del trabajo. Se concluye que, mientras estos profesionales ven en el trabajo asalariado una limitación a la libertad y al bienestar, perciben su trabajo creativo como la forma más completa y placentera de expresión de sí mismos. Esta investigación contribuye originalmente a los estudios sobre las nuevas realidades e identidades relacionadas con el trabajo.
\end{abstract}

Palabras clave: trabajo, autonomía, creatividad, autocuidado, autorrealización.
Ducange Médor*

\begin{abstract}
In this paper it's presented and interpreted the idea of a group of independent workers about work. The aim is to understand what does work mean to them. The data come from an ongoing investigation in which to know the process by which audiovisual professionals become independent and their assessment of their experience as autonomous is sought. The investigation is carried on twenty one in depth interviews and the observation of blogs and Facebook communities where they share perceptions about the work's world. The conclusion is that, while they perceive wage labor as a limitation to freedom and well-being, these professionals conceive their creative work as the most complete and enjoyable way of expression of themselves. Thus, this article originally contributes to the realm of studies on the new realities and identities related to work.
\end{abstract}

Keywords: work, autonomy, creativity, self-care, self-fulfillment.

- Postdoctorante en el Doctorado en Gestión de la Educación Superior, Universidad de Guadalajara. leduc.medor@gmail.com -

Fecha de recepción: 22 de octubre de 2015. Fecha de aceptación: 05 de abril de 2016. 


\section{Introducción}

Una de las concepciones más antiguas de la actividad laboral la interpreta como una condena, una tortura o maldición. La raíz latina del vocablo "trabajo" condensa esta concepción: el verbo latín tripaliare, del que deriva el tripalium, que se traduce al castellano como "trabajo", significa "torturar", "atormentar", y hace referencia a un objeto de tres estacas cruzadas con el que se torturaba a los reos (Machado, 2007).

Según Marzano (2011, pp. 146-147), el infinitivo tripaliare derivó en el sustantivo trepalium con el que los hombres del Medievo nombraban un "instrumento formado por tres estacas destinado a trabar a los animales para encerrarlos o curarlos". En palabras de De la Garza (2001, p. 12): "En la Antigüedad y la Edad Media hubo socialmente un desprecio por el trabajo, adjudicado a clases bajas o visto como castigo y penitencia".

El medievista Fossier (citado en Marzano, 2011, p. 148) afirma que en la Edad Media "Los que trabajan, y casi únicamente en provecho de los demás, son seres esclavizados, bajos, despreciables". Hoy aún pervive la concepción que hace del trabajo una obligación o imposición marcada de un penoso esfuerzo.

Otra visión del trabajo, también antigua y contraria a la anterior (Marzano, 2011), lo asimila a la actividad artística. Autónoma, creativa e intrínsecamente motivada por definición (Menger, 2009), la ocupación artística ha sido vista como alejada de la servidumbre de la necesidad y de las imposiciones sociales históricamente ligadas al trabajo percibido como condena.

La distinción fundamental entre estas dos formas de ocupación radica en la sumisión de la forma "trabajo" a la finalidad económica, y supone una escisión en la vida de quien la lleva a cabo: una parte la dedica a la actividad 
laboral a las órdenes de un tercero a cambio de una retribución, y la otra la ocupa en cosas con finalidad placentera y de sentido existencial (Bologna, 2006; Marzano, 2011).

Por otro lado, la finalidad de la actividad artística le es intrínseca y no es, en primera instancia, la ganancia económica. Idealmente, el individuo estaría enteramente comprometido y envuelto en su creación, que se haría una con las otras dimensiones de su existencia. No habría un tiempo para la creación y otro para la vida propiamente dicha, sino que esta consistiría en crear, de ahí que la actividad artística suela "colocarse bajo el registro de la vocación" (Buscatto, 2004, p. 51).

Esta es la visión ideal de la creación artística, que a menudo tiene dificultades para conciliarse con la realidad. No siempre es el arte el simple resultado de la "manifestación de la espontaneidad inspirada, porque se realiza bajo constreñimiento" (Menger, 2009).

Como sea, los que se definen como artistas parecen identificarse plenamente con esa concepción ideal de su actividad. Estos tienen una visión de su ocupación que transciende el terreno de lo rutinario, repetitivo, regulado, alienado, lo extrínsecamente motivado y heterónomo del trabajo sometido a la finalidad económica, y reinvindican para sí el mundo de la creatividad, de la autonomía, de la subjetividad, de la independencia, de la gestión y el control de su vida.

Esta concepción idealizada del quehacer artístico ha sido apropiada por otros profesionales que consideran su propio quehacer como "artístico", aunque su creación artística, al menos en su ejecución, guarda muchas diferencias con la actividad artística tradicional. En este grupo están incluidos los artistas digitales y otros en cuyas creaciones las tecnologías informáticas tienen un papel preponderante.

En este artículo se parte de las reflexiones en torno a la pregunta por el significado del trabajo de un grupo de 
profesionales independientes del medio audiosivual que se autodefinen como "artistas digitales" para ofrecer su visión del trabajo con base en su propia actividad.

El objetivo es mostrar, por un lado, la íntima relación que existe entre la concepción de estos individuos de la actividad laboral y su forma de trabajo, y, por el otro, cómo esta se liga con una forma de hacerse cargo de sí y de la construcción de su identidad. La tesis que se intenta demostrar es que esos trabajadores independientes conciben su trabajo como una actividad lúdica y placentera basada en la autonomía y la gestión libre de su tiempo y de su vida, y cuya realización conlleva el florecimiento de toda su existencia.

El presente trabajo está dividido de la siguiente manera: primero se expone la ruta metodológica seguida en la construcción de la investigación y el análisis; después, se presentan los datos empíricos, seguidos de una discusión teórica de los mismos; por último, se hacen algunas consideraciones finales.

\section{Método}

Entre octubre de 2014 y mayo de 2015 se entrevistaron veintiún profesionales freelance radicados en la Zona Metropolitana de Guadalajara, cuyas actividades se enmarcan en el campo del medio audiovisual y se basan en la aplicación de nuevas tecnologías informáticas.

Según la defición del artista que hace Bille (citado en Steiner y Schneider, 2012, p. 9) (a saber: "artistas son gente que trabaja en una industria creativa, tiene un empleo con contenido creativo"), los sujetos entrevistados son todos artistas. En la investigación de la que es parte este artículo se busca conocer los motivos y los procesos por los que esos profesionales llegan a convertirse en independientes, la valoración que hacen de su experiencia de trabajadores 
autónomos y sus formas de arrostrar la incertidumbre inherente a esta modalidad de ocupación.

La edad promedio de los entrevistados era de treinta y un años, y la edad de la mayoría variaba entre los veinticinco y los treinta y cinco años, todo esto al momento de las entrevistas. Los entrevistados tenían trayectorias laborales diversas y sus ingresos eran muy variados. El grupo estaba formado por once mujeres y diez hombres; cinco de ellos vivían con su pareja y tres tenían uno o dos hijos menores de edad. En el momento de las entrevistas, siete vivían con sus padres; los otros que no estaban en pareja lo hacían solos o con amigos.

Algunos de ellos habían pasado por periodos de trabajo asalariado, mientras que otros habían sido siempre freelance; había quienes combinaban el "freelanceo" con algunas horas de empleo asalariado, mientras que otros eran exclusivamente autónomos. Todos eran egresados universitarios con al menos una licenciatura terminada, y provenían de familias pertenecientes a los diferentes niveles de la clase media; a excepción de uno, todos tenían al menos a uno de sus padres con estudios de licenciatura. En la construcción de la muestra, se siguió la técnica de la "bola de nieve" y se procuró que fueran trabajadores independientes en el momento de la toma de entrevista, o que lo hubieran sido cuando mucho seis meses antes de aquella fecha; interesaba que su experiencia de freelance fuera reciente. El límite de la muestra fue determinado por el punto de saturación de la información.

Las entrevistas duraron entre cien y ciento ochenta minutos. Fueron todas grabadas, transcritas y analizadas con ayuda del software Atlas.ti 6. Fueron entrevistas semiestructuradas y giraron en torno a cinco ejes temáticos: la trayectoria laboral, la experiencia del trabajo independiente, la percepción sobre el trabajo, la asunción de la 
inestabilidad propia del ser independiente, y la visión a futuro en lo profesional y laboral.

Además de las entrevistas, se siguieron dos comunidades virtuales (en la red social Facebook) donde se acostumbra compartir imágenes, comentarios y reflexiones relativas al trabajo independiente. También se visitaron los blogs o páginas web de algunos de ellos. De estos sitios se pudieron obtener informaciones que reforzaron lo visto en las entrevistas.

En el análisis, se procura confrontar los discursos de los sujetos con su contexto social y los recursos teóricos que resultan más pertinentes para entender las lógicas subyacentes a sus creencias y prácticas y su perspectiva sobre su forma de trabajo. Para analizar los discursos, también se sigue a Alonso y Callejo para quienes "Los discursos no son sólo palabras, son formas de práctica social que nos remiten a [...] contextos pragmáticos, a nichos institucionales, a condiciones materiales y a prácticas no discursivas en un sentido estricto" (1999, p. 59).

En las narraciones que hacen los sujetos de sus prácticas o de su visión de la vida social se traslucen elementos articuladores del contexto social que perfila sus metas y valores y enmarca sus acciones (Mayer, 2004; Ruiz, 2009). El análisis del discurso de los informantes realizado se completa con el enfoque del curso de vida en la versión sociológica propuesta por Mayer (2004, p. 165): "Desde la perspectiva de la sociología, los cursos de vida son considerados no como las historias de vida personales de los individuos, sino como las expresiones dinámicas y reguladas de la estructura social”. Se parte del supuesto de que las vidas individuales son "parte y producto de un proceso sociohistórico de varios niveles" y que "están intrínsecamente ligadas a los cursos de vida de otras personas y a las dinámicas de los grupos sociales de los que son miembros" (Mayer, 2004, p. 166). 
La historia laboral de los sujetos de este estudio sucede en la época llamada "posfordista/postindustrial", que va de 1973 al presente. En lo laboral, dicha época es descrita por Mayer (2004) como de alta movilidad entre empresas y entre ocupaciones, de poca movilidad en los ingresos, y de desempleo, mientras que en lo temporal se caracteriza por la discontinuidad desestandarizada. Para Thoemmes, Kanzari y Escarboutel (2011), es un periodo de profundo malestar en el trabajo asalariado. Este contexto es importante para situar y entender la perspectiva de los entrevistados. Para las referencias a estos, y con el fin de mantener su anonimato, se utiliza un pseudónimo.

\section{El trabajo como apuesta placentera por la autonomía}

El argumento central de este texto es que el freelance del campo audiovisual percibe el trabajo como una forma de defender su autonomía, de divertirse y de cuidarse a sí mismo. Algunas de las investigaciones que han buscado descifrar los principales valores que los trabajadores independientes asocian al trabajo han encontrado que estos privilegian su "utilidad procedimental" por encima de la utilidad monetaria (Benz y Frey, 2008; Frey, Benz y Stutzer, 2004).

Este concepto se refiere al valor que se da al proceso (al cómo) por el cual se lleva a cabo una actividad cualquiera. Dicha noción entraña una preferencia entre el "cómo" y el "qué" o el resultado. Los autores descubren la autonomía como indicador predominante de la utilidad procedimental. Se presume que un profesional escoge trabajar como freelance o independiente por la importancia que otorga a su autonomía.

Uno de los desarrollos teóricos que mayor énfasis pone en el concepto de autonomía como vector central de las 
decisiones y preferencias humanas es la llamada teoría de la autodeterminación (en adelante, TAD).

Esta teoría establece que:

1. Los seres humanos tienen tres necesidades psicológicas profundas: de autonomía, de competencia (competence) y de pertenencia (belongness). Desde esta perspectiva, el desarrollo pleno de todo individuo pasa por la atención a estas tres necesidades. Son innatas (Deci y Ryan, 2000) y "constituyen los nutrimentos requeridos para la proactividad, el desarrollo óptimo y la salud psíquica de todo el mundo. Inherentes a la naturaleza humana, operan con independencia del sexo, la cultura y el tiempo" (Deci y Vansteenkiste, 2004, p. 25). La necesidad de autonomía apunta a la experiencia de orientar y de controlar uno mismo las propias acciones o de ser "agente causal, de experimentar volición y de actuar conforme a un sentido integrado de sí mismo" (Deci y Vansteenkiste, 2004, p. 25). La autonomía implica elección, integración y libertad. La necesidad de competencia concierne al deseo de tener control o dominio efectivo sobre el entorno y de funcionar eficazmente dentro de este. Entraña enfrentar y superar desafíos. Y la necesidad de pertenencia apunta a la "propensión universal de interactuar con, de estar conectado con y de sentir afecto hacia otras personas" (Deci y Vansteenkiste, 2004, p. 25).

2. Estas necesidades se satisfacen plenamente en la realización de acciones intrínsecamente motivadas que concurren a la consecución de tres metas o aspiraciones: relaciones significativas, crecimiento personal y contribuciones a la comunidad.

3. La satisfacción de dichas necesidades fundamentales mediante el logro de estas metas conduce a la integridad y a la autorrealización de los individuos (Deci y Ryan, 2000; Deci y Vansteenkiste, 2004). 
Deci y Ryan (2000) sostienen que competencia, pertenencia y autonomía han sido naturalmente seleccionadas porque ofrecen ventajas adaptativas a la especie humana. Definida como auto-organización y autorregulación, la autonomía habilita al individuo para especificar, jerarquizar y procesar sus necesidades en concordancia con las posibilidades ambientales (Deci y Ryan, 2000). Garantiza diversidad entre los individuos y, por lo mismo, sus contribuciones originales enriquecen el acervo de recursos adaptativos del grupo. Esto vale también para la competencia y la pertenencia. Visto desde esta perspectiva teórica, trabajar como freelance sería una respuesta a una motivación interna, a una necesidad intrínseca de autodeterminación, competencia y pertenencia. En este tabajo, el énfasis está puesto en la preferencia por la autonomía.

\section{I. La percepción freelance del trabajo asalariado}

Para los freelance, ser asalariado, o "godínez", ${ }^{1}$ significa llevar una vida poco emocionante, sin retos y con enclaustramiento en una oficina a lo largo del día. Es una vida con poco espacio para la creatividad, la inventiva y la libertad, y llena de mediocridad y aburrimiento. El "godinez" está siempre vigilado, limitado en sus movimientos y en su inspiración, y atado a su silla en una oficina gris en la que pasa las horas mirando desesperadamente el rejoj, deseando que pronto llegue la hora de salir del trabajo.

En un disco que lleva por título El lado oscuro de la oficina, el grupo musical "Los Godínez" incluye una canción intitulada "Godinean rhapsody", que es una especie de

I. Es difícil establecer con precisión los rasgos de quienes los independientes llaman "godínez". Por lo pronto, en la jerga de los freelance, "godínez" designa más o menos a los profesionales asalariados que cumplen un horario de oficina rígido (por ejemplo, de 9:00 a 18:00 horas), trabajan en estructuras de mando muy verticales y ocupan los niveles medios y bajos en esas jerarquías (para una mayor caracterización a la usanza de los freelance, véase: Pinto, 2015). 
himno de desencanto al trabajo asalariado. He aquí parte de la letra:

Yo no soy godínez, esto es temporal [...]

Cuando tenga treinta, voy a conseguir una buena chamba para ser feliz [...]

Yo no era godínez, el mundo me hizo así.

Yo no era godinez, quiero libertad.

Pasan treinta años, sigues endeudado, no te habla tu vieja, eres un esclavo (Los Godínez, 20I4).

Para el asalariado retratado en esta canción, su trabajo es una condena que él nunca eligió. Su insuficiente remuneración lo hace estar eternamente endeudado y sus condiciones laborales dificultan su relación de pareja, pero se consuela (o se autoengaña) pensando que es una situación pasajera, que vendrán otros tiempos en los que tendrá un buen empleo que lo hará feliz.

En la perspectiva del freelance, utilizando una idea de Marzano (2011), el oficinista es un esclavo voluntario, un "autónomo" que elige "libremente su estado de servidumbre" (p. 53). Así piensa, por ejemplo, una entrevistada (que fue excluida de la muestra por su perfil ocupacional) que pretendía formar un despacho de consultoría para empresas. Ella comparaba a la mayoría de los asalariados con una persona acostumbrada a recibir patadas. El día que no las recibe o que, más aún, se le felicita por su trabajo, exigirá ser tratada a patadas, otra forma de decir que los asalariados viven infelices en sus trabajos porque están demasiado apegados a la seguridad de un salario.

En un libro de consejos para freelance, una especie de gurú mexicana en estos terrenos escribe: "El cielo es el límite [...]. Ciertamente, el que trabaja por su cuenta tiene tantas posibilidades de crecer profesional y económicamente como esté dispuesto a trabajar por ello. No existen los límites del 
puesto, del tabulador, del jefe, etcétera" (Sánchez-Escuer, 2013, p. 40). En esta lógica, el asalariado es representado como el que no tiene sueños o los ha trocado por la "mezquina" seguridad de un empleo y un sueldo estables.

En los años setenta, surgió en el mundo de las empresas un discurso articulado en torno al interés por sustituir el modelo vertical fordista de organización del trabajo por uno más horizontal y flexible en el que se tomaran en cuenta los intereses y el crecimiento personales del trabajador (Marzano, 2011). En la actualidad, pulula un corpus discursivo gerencial cuyo objetivo es lograr que el trabajor se identifique plenamente con la empresa y se vuelva borrosa la frontera entre su vida privada y su vida laboral.

Escribe Marzano: "lo que está claro es que la empresa contemporánea busca presentarse como un lugar de evolución y de crecimiento personal" (2008, p. 114), todo esto sobre la base de la autonomía y la autogestión del trabajador. ¿Es verdad lo que se promete? ¿Se puede ser realmente autónomo como asalariado de una empresa? Los entrevistados opinaron que no, y así piensa también Marzano. Según ella, en las empresas

el trabajador modelo es un hombre "comprometido" que debe "creer" en su trabajo y encontrar en él la felicidad; debe ser adaptable, flexible y polivalente, y tiene que encontrar su realización personal en algo que lo aliena. En lugar de las prescripciones tradicionales, vemos emerger un nuevo sistema de obligaciónes que exige de los trabajadores que sean al mismo tiempo más autónomos y más sumisos (Marzano, 20II, p. 54).

La cuestión es que el discurso empresarial de las últimas tres o cuatro décadas se ha presentado bajo un traje ético integrado por una presunta apuesta por la subjetividad, la felicidad, la libertad de los trabajadores, pero con una visión instrumental y engañadora de esos valores. 
El principal y casi único interés que tienen las empresas es maximizar sus márgenes de ganancia. El cambio en el discurso que acompaña a su gestión del trabajo no obedece a una preocupación genuina por el bienestar y la autorrealización de los trabajadores, sino a la convicción de que se gana más logrando que el trabajador se involucre al hacerle creer que es libre y es lo más importante para la empresa, "Lo que tiene como consecuencia una adaptación constante de cada uno a lo que se espera de él. Creyendo en su crecimiento, el individuo desaparece bajo las exigencias de excelencia que la empresa le impone" (Marzano, 2008, p. 115).

Una paradoja aflora en esta realidad laboral. Al tiempo que se ofrece autonomía y libertad a los trabajodores, se les exige que se sometan al control y la presión de los jefes. Esto conduce a lo que Marzano llama esquizofrenia racional: los asalariados están sometidos constantemente a unas exigencias contradictorias que los conducen al desequilibrio.

A la luz del análisis de esta autora y de otros (por ejemplo, Thoemmes, Kanzari y Escarboutel, 2011), es inevitable afirmar que en el actual mundo del trabajo asalariado hay todo menos autonomía real. La conclusión no podría ser más sombría: "Mientras que ayer se reivindicaba la autonomía y la libertad para limitar la dependencia de los asalariados por parte de su empleadores, hoy, impuestas desde arriba, parecen volverse contra los trabajadores" (Marzano, 2011, p. 69).

Muchos de los freelance tienen la experiencia del trabajo dependiente o asalariado, conocen a muchos asalariados, tienen una percepción muy cercana a la de Marzano respecto a esta modalidad de ocupación: les resulta sombría. De ahí un poco su decidida apuesta y su valoración de la autonomía, la autogestión y las posibilidades de crecimiento que parece procurarles el trabajo freelance. 


\subsection{El tabajo freelance como autodeterminación}

La visión negativa que tienen los freelance sobre el trabajo asalariado obedece, en parte, a que para ellos el proceso creativo, que consideran como puntal de su ocupación, no puede supeditarse a un horario; no se puede ser creativo sentado forzosamente frente a un escritorio en un determinado lapso. Suscribirían encantados estas palabras de Adorno sobre Nietzsche: "Pero es difícil imaginarse a Nietzsche sentado hasta las cinco a la mesa de una oficina en cuya antesala la secretaria atiende al teléfono como jugando al golf [una vez] cumplido el trabajo del día” (Adorno, 1987, p. 130).

Para el freelance, semejante situación implicaría cierta aniquilación o la enajenación total. De ahí la necesidad de prohibir esta forma de trabajo, so pena de ver desquiciados a cuantos están sometidos a sus reglas. El lema del freelance puede expresarse en estas palabras: "Ilusionados, nos identificamos con las cuatro primeras letras de la palabra freelance ("libre")" (testinomonio de una diseñadora, citado en Fleishman, 2004, p. 34).

A diferencia del asalariado, el trabajo freelance obedece a ritmos diferentes que no pueden establecerse con base en una gestión empresarial uniforme del tiempo. El horario de trabajo del creativo debe ajustarse a su creatividad y no al revés. Una imagen de una comunidad de Facebook llamada "Diseño Freelance" presenta un cerebro sentado en una silla en la playa y la leyenda: "Mi vida no está llena de momentos, pero sí de insights".

Si la vida no es entonces una acumulación de momentos, como puede ser la acumulación de años, meses, días y horas en una oficina donde el trabajo se basa en la eterna repetición de lo mismo, sino que está llena de insights, de arrebatos de creatividad, menester es generar las condiciones propicias tanto para el advenimiento de esos insights como para su materialización en una obra, que en este caso 
puede ser desde una ilustración, un diseño cualquiera, una estrategia de publicidad, una edición, etc. Así el caso de Karim (diseñador gráfico e ilustrador):

Yo busco mucho momentos como de estabilidad, un poco personal o emocional, para trabajar proyectos creativos. A veces, en todo el día, digo: "ihíjole!, ahora no me puedo sentar a pensar y aterrizar una idea". Entonces, espero que sea de noche, a veces, a las diez de la noche empiezo a trabajar y trabajo hasta las tres de la mañana. $Y$ es cuando fluye mejor (entrevista personal, 2014a).

Para este y todos los entrevistados, una de las virtudes de ser independiente es la posibilidad de organizar su tiempo como mejor parezca. Esto permite poder combinar diversos proyectos, "liberarse de ataduras", nunca aburrirse y, como dice Karim, "Siempre estár terminando y empezando nuevos proyectos" (entrevista personal, 2014a). Yvon y Clot (2001, p. 73) definen trabajar como "recrearse a sí mismo y su medio" y, al mismo tiempo, "renovarse a sí mismo".

Esto conduce a la imposibilidad de separar de los otros momentos de la vida el tiempo de trabajo. Dado que la vida no está llena de momentos, el tiempo de ocio puede ser también de trabajo, y viceversa. Como observaron otros en relación con los jóvenes artistas independientes en la ciudad de México: "La línea que divide los tiempos de ocio del trabajo es cada vez más tenue" (Gerber y Pinochet, 2012, p. 20).

En la percepción de Urteaga, “Trabajar y reventarse [sic] formaban parte de la misma realidad, vivir el presente, tener la sensación de estar controlando/dirigiendo su vida. En la medida en que percibían el trabajo como placer, como parte de la diversión y la diversión como trabajo, las fronteras entre el ocio y el trabajo eran muy borrosas" (2012, p. 31).

Hay quienes ven en esa indistinción entre ocio y trabajo una forma de autoexplotación de los profesionales independientes (Urteaga, 2012). Dada su condición de inseguridad 
presente y futura, estarían obligados a integrarse al mismo tiempo a diversas ocupaciones o a saturarse de proyectos a fin de generar ahorros para los momentos de pocos ingresos (Menger, 2014). Para muchos de los entrevistados, los momentos de diversión pueden ser momentos propicios para contactar con potenciales clientes o establecer alguna estrategia de colaboración con algún colega, por lo que el trabajo nunca acaba o habría una superposición entre tiempo de trabajo y tiempo de diversión. Siendo así, ¿constituye esto una forma de autoexplotación?

Si se formulara esta pregunta a cualquiera de los freelance de la investigación realizada, es seguro que respondería que quienes son en verdad explotados o autoexplotados son los "godínez", porque están desprovistos de su tiempo, de su autonomía y a menudo son obligados a hacer cosas que no les gustan y a trabajar horas por las que no reciben un pago. En cambio, el trabajo del freelance se confunde con la diversión, con el recreo. Fleishman (2004, p. 32), reporta un testimonio de una diseñadora estadunidense que coincide plenamente con los informantes del presente estudio:

En el fondo, soy un agente solitario, disfruto de las libertades de trabajar como freelance. Trabajar por tu cuenta es arriesgado, tienes que hacer mucho trabajo aparte del proceso creativo. Pero todas las recompensas son para ti. Es la libertad de trabajar donde y cuando quieres, la autodeterminación de ser capaz de trabajar sólo con aquellos con los que quieres trabajar, llevando tu negocio por el camino que tú quieres, la autosatisfacción de alimentar un negocio y de verlo crecer y madurar.

Para los freelance, se puede llegar a trabajar mucho, pero poco importa esto en relación con la libertad, la autodeterminación y la autosatisfacción que conlleva el proceso creativo. 


\subsection{El trabajo como placer y diversión}

Urteaga reporta lo siguiente sobre los llamados artistas "trenders" de la Ciudad de México:

Los trends se ubicaban de una manera particular entre los generadores y difusores de novedosos estilos de vida y de trabajo. Realizan distinciones entre empleo (sujeción a horarios y realización de funciones y/o actividades no propias) y trabajo (placer, creatividad, innovación, libertad, obtención de satisfacción estética) (Urteaga, 20I2, p. 30).

Al preguntar a Julio (diseñador gráfico) sobre el significado que tiene para él el trabajo y sobre lo que le motiva a trabajar, responde:

¿Qué significa? Pues como he trabajado muy pocas veces, no te lo puedo decir [ríe]. Es que para mí no significa trabajo, para mí esto es divertirme; es pesado, o sea, a veces es muy pesado, pero no es trabajo. Trabajo es cuando haces algo que no te gusta, trabajo es algo que tienes que hacer, pero cuando haces algo que te gusta no es trabajo, es diversión (entrevista personal, 2015a).

Mario percibe su "trabajo" de fotográfo especializado en fotografías de $360^{\circ}$ de manera análoga:

Para mí esto no es un trabajo, no lo veo como un trabajo [...]. Porque como viene desde mi hobby, un hobby nunca lo ves como un trabajo, aunque te cueste trabajo y que inviertas tiempo y dinero, pues no lo ves así, no lo contabilizas [sic] de esa manera. Entonces yo creo que es un poquito eso, no sé cuándo estoy trabajando y cuándo no [ríe] (entrevista personal, 20l4b).

Según los entrevistados, la diferencia entre el (no)trabajo (creativo) del freelance y el trabajo (no creativo) del asalariado común no radica en la dificultad o lo cansado que 
puede resultar su realización, sino, aparte de la autonomía, en el disfrute o la diversión experimentado en su ejecución.

Para la ilustradora y diseñadora Marú, el trabajo "tiene que ser algo disfrutable, tiene que ser una pasión" (entrevista personal, 2014c). Es también la percepción de María, fotógrafa, ante la pregunta "¿para ti qué significado le das al trabajo?":

¿El trabajo? Pues se me hace bonita tu pregunta. Yo creo que el trabajo no existe, para mí no existe el trabajo. O sea, trabajo es algo que te cueste trabajo hacer, ¿no? Para mí en lo personal no, yo no trabajo [...]. Vivo y me divierto, porque de lo que hago todo me gusta, todo me gusta. $O$ sea, si voy a un evento, ni siquiera siento que "iay, tengo que ir a trabajar!”. No. O sea, es: “iay, qué padre!”. Entonces mi vida es la fiesta, o sea disfruto muchísimo ir a una fiesta y los momentos más felices, pues, iqué afortunada!, porque hasta me pagan. A veces viajo con las personas gratis, por "trabajo", entre comillas, porque no es trabajo, es estar viendo gente nueva, paisajes nuevos, locaciones nuevas, historias nuevas (entrevista personal, 20I5b).

Según Coulangeon (2004, p. 87), estos profesionales tenderían a "la articulación de una fuerte valorización de las satisfacciones experimentadas en el trabajo en compensación de la inestabilidad de las condiciones de empleo”. Así mismo, tenderían a acentuar aún más las virtudes de la inestabilidad por cuanto "contrastan con los aspectos negativos generalmente ligados al trabajo permanente" (p. 87).

Parecería que el principal punto de inquietud del trabajo independiente, la inestabilidad, sería a la vez, su principal virtud, dado que ofrece una movilidad que, a los ojos del freelance, es la condición misma de realización de sí en el trabajo. Sobre este último punto, los entrevistados le dan toda la razón a Coulangeon: el tener que cambiar constantemente de proyectos, estar siempre activos y creativos, enfrentando nuevos retos artísticos o intelectuales es visto 
por los freelance como el principal combustible de su florecimiento personal.

Según Menger (1991, p. 63), "Está en la esencia de las actividades débilmente o nada rutinarias (de las que las artes son una incarnación paradigmática) otorgar satisfacciones sicológicas y sociales equivalentes al grado de incertidumbre sobre las posibilidades de éxito", sin que esto signifique necesariamente una sobreestimación de los beneficios versus una minimización de los riesgos.

$\mathrm{Al}$ menos tres de cada cuatro entrevistados reconocen que no todo el mundo puede ser independiente y respetan a quienes están cómodos en su dependencia de la "seguridad" del empleo asalariado o "de la quincena", como dijo una entrevistada. A pesar de esto,ellos se reconocen como "no hechos" para estar cotidianamente a las órdenes de un jefe, y menos aún para cumplir un horario rígido dando "horas nalga", según expresaron varios.

Estos profesionales se parecen quizás a aquellos que, según Nietzsche $(2001, \S 42)$ "prefieren morir de inanición antes que dedicarse sin placer a su trabajo: aquellos hombres selectivos, difíciles de satisfacer, a los que no los contenta una ganancia abundante, cuando el trabajo mismo no es la ganancia de todas las ganancias". El filósofo incluye en primer lugar en esta categoría de individuos a los artistas.

Aparte del placer que hallan en hacer lo que hacen, usando sus fantasías creativas, su inventiva y su autonomía, disfrutan que el cliente, o quien les compre algún objeto (alguna ilustración, etc.), quede contento o satisfecho. ${ }^{2}$ Hacen los encargos con el mismo empeño con que harían algo personal. Esto les permite involucrarse plenamente en lo que hacen y entregar al cliente algo que bien pudieran 
querer para ellos mismos. Así es la visión de Celestina sobre lo que hace:

Es que yo no lo veo como trabajo. El trabajo es así como costoso: "iay, el trabajo!”. No, yo más bien hago cosas que disfruto, que sirven para alguien. Me gusta lo que hago y gano dinero. $O$ sea, si no tuviera que trabajar para un cliente, haría lo mismo pero para mí. Por ejemplo, podria estar haciendo una página web que fuera para mí [...]. O sea, todo lo que hago para mis clientes lo voy a hacer, pero para mí, después, para mi proyecto, o lo que vaya a hacer. $Y$ dices: jay, claro que le echo ganas! ¡Claro que lo disfruto! Y así. Sí, hacer lo que me gusta es básicamente el freelance (entrevista personal, 20I4d).

Según los entrevistados, es trabajo la ocupación de las personas que a cambio de un cheque cada quince días o cada mes los obliga a hacer algo sólo por la obligación de hacerlo, pero cuya realización no los envuelve ni, por lo general, les divierte. Desde esta visión, todo aquello que se realiza por placer o con gusto no puede ser llamado "trabajo". Así es el significado que da Susana (diseñadora e ilustradora editorial) al trabajo:

Principalmente que me deje hacer lo que a mí me gusta hacer, por ejemplo, en este caso que estoy ahorita en el trabajo este, como a mí me encanta ilustrar y ahí es lo que hago y me pagan por ilustrar, entonces está muy chido, pues, trabajar en algo que te guste, porque ni siquiera sientes que es trabajo, entonces todo el día [estás] haciendo lo que más te gusta y lo disfrutas. Entonces para mí básicamente es eso, estar haciendo lo que realmente me gusta (entrevista personal, 20I4e).

E14 es una diseñadora que después de tres años de ser exclusivamente freelance, para el momento de la entrevista hacía cuatro meses que había vuelto a ser asalariada en una casa editora de libros escolares; combinaba este empleo con el "freelanceo". 
Junto con otros cuatro entrevistados en la misma situación, ella comparte, entre otras cosas, una visión de su trabajo asalariado como un "no trabajo", porque lo hacen, dicen, por gusto y con gusto, les permite ser plenamente creativos o "ellos mismos" y tienen plena autonomía en su realización. Aunque por ser un trabajo dependiente se reciben "lineamientos", es decir, no se hace todo como se quiere, sí hay libertad y, además, cada uno hace lo que disfruta hacer en un ambiente de trabajo que también se disfruta.

Esto es una evidencia de lo que Benz y Frey (2004 y 2008) llaman "utilidad procedimental". La mayor satisfacción que estos individuos experimentan en su trabajo ocurre en el proceso del mismo, y sólo de manera secundaria en la utilidad pecuniaria. Hacer lo que a uno le gusta en un ambiente de disfrute garantiza una mayor entrega en el proceso y, quizá, mejor calidad en el resultado.

Para Adorno,

Pocas cosas distinguen tan profundamente la forma de vida que le correspondería al intelectual de la del burgués como el hecho de que aquel no admite la alternativa entre el trabajo y el placer. El trabajo [...] es placer aun en el esfuerzo más desesperado. La libertad que connota es la misma que la sociedad burguesa sólo reserva para el descanso, a la vez que, mediante tal reglamentación, la anula (1987, p. 129).

No sería exagerado asimilar al intelectual adorniano con los profesionales freelance de la presente investigación, y al referido "burgués" con su contraparte "godínez". Con Nietzsche, se podría decir que los freelance "aceptan el trabajo y la penuria con tal de que estén asociados al placer" y "no temen tanto al aburrimiento como al trabajo sin placer" (Nietzsche, 2001, § 42).

El principal aliado del placer es la espontaneidad. El placer desafía todo horario. Y como el trabajo que entraña placer es el que se desarrolla en plena autonomía, en la 
perspectiva de los freelanceros el verdadero trabajo (autorrealizador) es el que realizándose en autonomía procura placer.

No resulta extraño que para Angel, fotógrafo profesional publicitario, el trabajo soñado sería aquel para el que no tuviera que cobrar y cuya gratificación o recompensa estuviera en la misma realización. Sería el trabajo (fotográfico) que hiciera por el puro placer de hacerlo, que disfrutara haciéndolo sin presión ni encargo.

Algunos estudiosos (Steiner y Schneider, 2012; Benz y Frey, 2004 y 2008) reportan un mayor nivel de satisfacción (o de felicidad) de los artistas y trabajadores independientes que de los dependientes. Esta diferencia se explica, por un lado, por la mayor independencia y autonomía de que gozan los primeros y, por el otro, por la mayor importancia que dan a beneficios no pecuniarios como la utilidad procedimental (Benz y Frey, 2004 y 2008) o al cómo de la realización de su trabajo, con respecto a la que dan a la utilidad final del mismo (ingresos).

Por trabajar de manera autónoma y estar más interesados en su autonomía laboral que en la retribución económica, los independientes estarían más felices en su trabajo que los asalariados. Los datos aquí recabados sólo permiten conjeturar esto, aunque, como se apuntó, hay evidencias en la literatura que sustentan esta afirmación.

Lo que sí se puede sostener es que todos los entrevistados reportaron estar felices de la elección de su modalidad de trabajo y satisfechos con su vida de freelance. Justo esto quisieron expresar Benz y Frey (2008) al afirmar: "Ser independiente es algo grandioso" (p. 1). ${ }^{3}$ Por todo eso, para los freelance trabajar significa apostar por la autonomía, ser libre. 


\section{Trabajo y cuidado de sí}

Para los freelance, trabajar es también una forma de cuidado de sí en dos aspectos principales: el cuidado de su vida o de su persona y la gestión de su tiempo. Antes de abordar estas cuestiones desde la voz de los profesionales, debe revisarse cómo se entiende el cuidado de sí en la visión de Michel Foucault.

\section{I. El cuidado de sí en la obra de Foucault}

Según Foucault, en la filosofía antigua, el "cuidado de sî" implicaba "establecer consigo mismo una cierta relación de dominio, de señorío" (Foucault, 1999, p. 399). "Cuidar de sí" significa superarse a sí mismo, dominar las pasiones, los apetitos. Lo fundamental es que el "cuidar de sí" tiene como fin último "ocuparse de sí en el presente, es para sí mismo y tiene como fin uno mismo" (Foucault, 2001, p. 80).

Cierta preocupación por educar a los ciudadanos griegos y romanos para ocuparse de síatraviesa la filosofía antigua desde Platón hasta Plutarco, pasando por los estoicos, los epicúreos y los cínicos (Foucault, 2001 y 1999). Para todos ellos, hay una relación estrecha entre el "cuidado de sî", la libertad y la ética. Según Foucault (1999, p. 397), "la ética, en tanto que práctica reflexiva de la libertad, giró en torno a este imperativo fundamental: 'cuídate de ti mismo"'.

Por su relación con la ética, ese cuidar de sí era indispensable para poder conducirse con bien y ser libre: sólo quien se ocupa de sí es capaz de vivir conforme al bien y a la libertad. El individuo virtuoso es aquel que sabe cuidarse siendo dueño de sí mismo. Uno debe cuidar de sí en tanto es capaz de muchas cosas: de conocer, de relacionarse con los demás, de gobernar la ciudad y a los demás.

Se cuida al elemento más importante en uno mismo, que es el alma. Esta parte "divina” de la persona es la que merece el más alto cuidado. Al cuidarla, se entra en contacto 
con lo que hay de divino en uno, llega uno a conocerse en lo más profundo. Por eso, el cuidado de sí consiste en el conocimiento de sí (Foucault, 2001).

$\mathrm{Al}$ conocerse a sí mismo tanto en sus virtudes o fortalezas como en sus pasiones, sus afectos e inclinaciones, el individuo podrá liberarse, emanciparse, "satisfacerse" o "disfrutar de sí mismo" (Foucault, 2001, p. 83). El cuidado de sí y la autonomía o la libertad se implican mutuamente. El cuidado de sí de los freelance mediante el trabajo se asemeja a la visión antigua de esta práctica.

\subsection{El trabajo como cuidado de sí, o cuidar de sí como una manera de trabajar}

La primera dimensión del trabajo freelance como cuidado de sí consiste en la atención a la persona, la salud y el bienestar propios.

E4 es licenciada en comunicación y como freelance se dedica a la ilustración y al diseño de páginas web. Recién egresada de la universidad, entró a trabajar en una empresa de mercadotecnia donde hacía diseño web y trazado de mapas mercadológicos. Según cuenta, tenía un buen sueldo y prestaciones. Permaneció en ese empleo un año y algunos meses. Lo abandonó justo en el momento en que empezó a tener la seguridad de que quería dedicarse a freelancear: tenía clientes de ilustración y contactos de la universidad que la promovían. Aunado a eso, empezó a enfermarse y el ambiente de trabajo empezó a resultarle tedioso porque no tenía retos ni visión a futuro. Ya dominaba todo e iba a seguir haciendo lo mismo a partir de entonces. Su labor se volvió rutinaria. Quería algo que la retara, que fuera siempre novedoso, por eso se dedicó a ser freelance.

Ya se ha descrito la manifiesta aversión de este tipo de profesionales hacia la rutina, la repetición y el trabajo exento de retos. Esta experiencia de E4 la han conocido todos los otros entrevistados que en algún momento trabajaron 
para alguna empresa. Uno de los atractivos que atribuyen al ser independiente es la posibilidad de aprender en cada nuevo proyecto, en toda nueva colaboración. No hay dos trabajos idénticos; cada nuevo encargo implica la combinación de destrezas distinta a la anterior y la generación de ideas nuevas. Se aprenden cosas nuevas para la realización de un nuevo proyecto, y su ejecución misma conlleva otros aprendizajes.

Beaucage y Bellemare (2007, p. 18) reportan que una de las cosas que más valora de su trabajo un grupo de independientes canadientes es la necesidad de "ampliar constantemente sus conocimientos y sus competencias"; a la par de esto, los retos inherentes a la diversidad de proyectos les permiten descubrir "habilidades y recursos personales" antes ignorados. Para Erika, licenciada en artes audiovisuales, su principal motivo para trabajar es el "tener que aprender", son los "nuevos retos intelectuales", la posibilidad de "conocer nuevas personas y el hacer" que implica. Agrega: "Trabajar es estudiar al mismo tiempo, trabajar es vivir y conocer gente y experiencias nuevas" (entrevista personal, 2014f).

En la interpretación de Foucault, en el mundo antiguo una de las dimensiones del cuidado de sí consistía en conocerse a sí mismo. Hay una correspondencia profunda entre epimeleisthai heautou y gnônai heaunton ("cuidar de sí” y "conocerse a sí mismo").

Angel, fotógrafo publicitario y diseñador gráfico, cuenta que "el ambiente de trabajo" en una televisora donde laboró por tres años en calidad de diseñador digital "estaba padre [sic]”; tenía buena remuneración y su horario laboral le permitía realizar encargos como freelance. "Era un trabajo padre, entretenido y cómodo, con horarios flexibles dependiendo de las necesidades" (entrevista personal, 2015c).

Renunció porque detectó que la fuente de empleo no le ofrecería crecimiento: había aprendido todo lo que tenía que 
aprender, dominaba todos los requerimientos del trabajo y no esperaba ninguna novedad en cuestión de aprendizaje. Le perdió interés y lo dejó para volver a un trabajo anterior en un despacho de fotografía donde se estaba incursionando en campos nuevos, como el video. Ahí había posibilidad de crecer, de aprender más. Como se ha dicho, ser freelance abre posibilidad de aprendizajes. Y retarse, superarse, renovarse constantemente por el aprendizaje es propio del cuidado de sí.

Julieta atribuye la merma en su salud que sufrió durante su paso por una empresa de marcadotecnia a lo tedioso que a la larga resultó su ocupación y al poco tiempo y ánimo de que entonces disponía para ocuparse de sí misma. Al convertirse en freelance pudo ganar el tiempo y la disposición para conocerse y cuidar de sí:

Y en el diario, tienes que tener una estrategia para eso de los días difíciles, tienes que tener una forma de conocerte, pues, cómo trabajar, cómo... qué canciones te mantienen activo, qué comida, o sea, todo tiene que ver, hasta lo que comes. Eso sí, comer en las horas que, mínimo, tres veces al día, ir al baño cada dos horas, hacer ejercicio, porque también si no estás bien, si te matas, te desvelas y todo [...] porque para ser freelance tienes que tener toda tu estrategia, tener todo el empuje y contactos [...]. Pero también tienes que tener salud, tienes que tener... estar feliz (entrevista personal, 20l4g).

No parece exagerado afirmar con E13, publicista con maestría en artes de la publicidad, la existencia de cierto espíritu, de un estado de ánimo freelance caracterizado, entre otras cosas, por el amor a la autonomía o a la independencia, por la capacidad creativa y el compromiso con uno mismo: con su bienestar, su desarrollo, su felicidad, su excelencia. Dicho espíritu sería la concreción de las tres necesidades básicas que según la TAD orientan las motivaciones, los deseos, las acciones de los individuos. 


\subsection{Trabajo y cuidado de sí en la gestión del tiempo}

El trabajo como cuidado de sí es también gestión y dominio sobre su tiempo. Sin duda, uno de los terrenos donde se manifiesta con mayor claridad la oposición, si la hay, entre los asalariados y los freelance es en el manejo y la relación con el tiempo.

Ya se ha referido la importancia que tiene para los independientes la posibilidad de gestionar su tiempo como les resulte más propicio según su creatividad, su descanso, su ocio, su proyectos personales, etc. Aquí resulta provechoso enfatizar otro aspecto del manejo del tiempo que se podría denominar "la relación con el tiempo". Los entrevistados refieren esto al contrastar su relación de ciertos días de la semana con la de los asalariados. Aquí las palabras de Emmanuel, fotógrafo independiente:

El valor que le dan los godínez a los domingos es una cosa impresionante. Por decir, una cosa que me doy cuenta mucho en la diferencia de lo independiente son los lunes. A mí me gustan mucho los lunes porque es cuando me emociono de ver todo lo que voy a hacer en la semana, y es cuando me despierto como con más energía y con la mente más clara de una semana nueva, y me despierto muy emocionado y no sé, como que traigo un punch energético más grande, siendo que la gente [los "godínez"] que entra a trabajar los lunes despierta más cansada. Dicen: "iay!, a empezar otra semana otra vez". O sea, como que nada más están esperando el viernes y en realidad yo el lunes es como... el lunes en la mañana yo creo que es el día en que más funciona mi cerebro, mi creatividad (entrevista personal, 20l4h).

Es socorrida la creencia sobre el lunes como día odiado por los empleados de oficina. Al respecto, dice Gilberto: "Casi todos los empleados que conozco odian llegar a su oficina el lunes, aunque estén en un trabajo que les fascina. Yo lo veo en Facebook. Casi todos dicen: ‘chingada madre!, ya llegó el lunes”' (entrevista personal, 2014i). El grupo Los Godínez 
recoge esta situación en su ya referida canción "Godinean rhapsody" al rematarla con los versos: "Hay una luz al final del túnel, hay una luz al final del lunes" (Los Godínez, 2014).

En términos estrictos, para los freelance no hay una separación entre días-horas de trabajo y días-horas de descanso. Cualquier día de la semana resulta adecuado para trabajar o descansar y divertirse. Esto es algo que valoran los entrevistados sobremanera de su condición de independientes.

El gran atractivo de esta relación con el tiempo radica en su rechazo a la heteronomía y a la rutina o la monotonía, por cuanto el horario rígido y repetitivo de oficina es contrario a la creatividad o, según Margarita, otra entrevistada, "deshumanizante". Así narra el valor que tiene para ella disponer de su tiempo con libertad:

\begin{abstract}
Al final de cuentas, lo importante es que al ser dueño de tu tiempo tú lo administras, lo administras como prefieres y te da más libertades. Por ejemplo, ahora que me gusta mucho irme en la bici[cleta] de montaña, puedo ir entre semana cuando la mayoría de mis amigos ya tienen que estar a las nueve de la mañana en una oficina, y para estar a las nueve de la mañana en una oficina si quieres ir a [utilizar] la bici[cleta] de montaña te tienes [sic] que arrancar a las seis de la mañana, lo cual es demasiado temprano. Entonces, yo sí puedo irme a la bici[cleta] de montaña entre semana, llegar aquí y trabajar a las diez de la mañana sin ningún problema (entrevista personal, 2015d).
\end{abstract}

Este manejo de su tiempo con relativa libertad y acomodo a sus necesidades de trabajo, entretenimiento o descanso es un privilegio que los freelance reconocen gozar y que puede ser deseado por quienes tienen un trabajo dependiente.

Según Elias (2010), el tiempo es una forma de coerción social: permite la integración de los individuos en sus sociedades. Constituido en habitus social, regula en parte las interacciones entre estos y la vida personal de cada uno. Dada su centralidad en nuestras sociedades, el trabajo 
dependiente constituye un espacio donde se vive de forma sensible dicha coacción. En cambio, el trabajo autónomo ofrecería la posibilidad de sustraerse un poco a esos constreñimientos, ofreciendo cierta capacidad de manipular el tiempo.

Itzel tiene una larga carrera como productora audiovisual en cine documental, videos comerciales y musicales, campañas publicitarias, etc. Cuenta que en todos los trabajos que tuvo se preguntaba por qué no podría tener la libertad para decir que había terminado y que podía dedicarse a hacer otras cosas. Le frustraba que el tiempo no fuera de ella. La idea de que hay que estar en la oficina porque hay que estar, aunque no haya trabajo ni nadie que vaya a solicitar nada, le resulta "chocante". El privilegio de ser "dueña de su tiempo" le da la opción, dice, de trabajar largas jornadas cuando es necesario y, a la vez, de pasar muchas más horas con su familia, con sus hijos. Y, al igual que Margarita y otros más, ciertas mañanas puede dejarlo todo e irse a practicar su hobby: el golf.

Para ella, es una "bendición poder estar aquí [jugando golf] en un martes por la mañana y aventarme de nueve de la mañana a dos de la tarde aquí" (entrevista personal, 2015e); el poder decirle a su marido (dueño de un negocio): “vámonos tal día', [...] [e irse] sin tener que estar viendo calendarios ni nada [...] es increíble" (entrevista personal, 2015e). A este respecto, hay total coincidencia entre todos los entrevistados: señalan la gestión libre del tiempo como de lo más entrañable de ser freelance. Así lo expresa Karim:

Este es un punto a favor increíble, lo del tiempo. Poder decidir tu manera de combinar un proyecto con otro, poder decir cuándo descansar de un proyecto y concentrarte en otro, poder decirle a un cliente que no vas a estar [...] son implicaciones de movilidad. Y estar libre de ataduras, para mí, creo que es lo más valioso (entrevista personal, 2014a). 
Según los freelance, los asalariados (los "godínez") viven obsesionados por el viernes. En el ya mencionado grupo "Mundo Godínez" de Facebook pululan las imágenes que muestran a empleados en traje y corbata con la etiqueta: "iPor fin es viernes!... vamos a echar desmadre [sic]” (Facebook, 2015).

A diferencia de los freelance, quienes pueden hacer en cualquier día de la semana lo que según el cánon dominante de la utilización y disposición del tiempo se debe hacer en, por ejemplo, viernes o sábado, para los asalariados el viernes es el día más deseado de la semana, es el de la liberación momentánea de la rutina, del estrés y del tedio de su empleo.

Esto es contrario a lo que expresa Gilberto sobre su forma de vivir los días y el impacto que tiene esto en su ambiente familiar y en su propia vida:

Yo, hay domingos [que] es [sic] como si fuera sábado. Me echo mis tragos, vamos a comprar una botellita de vino mi esposa y yo, cenamos en la casa como si fuera sábado. Esto yo creo que mejora mucho el estado de ánimo de una casa. El estado de ánimo de una casa cuando no está esa presión es precioso, muy diferente. Es una energía increíble. Luego, entre semana [...], si ya el martes digo que sea viernes, yo lo hago viernes. Yo me voy a mi casa tranquilamente y trabajo desde ahí y estoy con mis hijas (entrevista personal, 20l4i).

En esta manera de usar el tiempo y de estar en el tiempo hay libertad, no anarquía; responsabilidad y disciplina, no lo contrario. Todos los profesionales entrevistados hacen énfasis en la necesidad de organización, de una irrestricta disciplina de trabajo y un fuerte sentido de responsabilidad, de seriedad y de compromiso en la realización de los encargos o proyectos como condición sine qua non de la sobrevivencia o del éxito como freelance. Para Mario, el lema de todo freelance debería ser "Don't panic, organise", frase que él mismo tiene inscrita en una pared de su estudio. En 
resumidas cuentas, organizarse y tener dominio sobre su ritmo de trabajo mediante la gestión independiente y una relación dinámica con el tiempo abonan a la apropiación de su vida, al cuidado de sí.

\section{Conclusiones}

En este texto se partió de la percepción de los profesionales independientes del audiovisual para intentar reconstruir el signicado que ellos atribuyen al trabajo. Por un lado, se mostró que el trabajo creativo entraña para ellos una manera de reivindicar y resaltar su autonomía, misma que se materializa en la gestión de su tiempo conforme a sus necesidades, la combinación de diversos proyectos, el disfrute en la ejecución de estos, la flexibilidad o la movilidad. Todos consideran que su trabajo creativo no puede constreñirse al espacio limitado de una oficina ni a un horario establecido por otros.

Estos trabajadores de las industrias creativas son portadores de un discurso muy antiguo que establece una distinción entre la actividad creativa, artística o intelectual, y el trabajo propiamente dicho. Aquella es sinónima de libre y placentero despliegue de las fantasías creativas en la producción de bienes simbólicos, mientras que el trabajo es percibido como sacrificio involuntario en virtud del arrastre de las fuerzas de la necesidad. Creación, libertad y deleite se oponen a repetición, necesidad y aburrimiento.

Asimismo, se mostró que para estos profesionales la actividad laboral significa cuidado de sí. En la interpretación y resconstrucción de esta segunda faceta del trabajo freelance, con apoyo en la lectura de Foucault de dicha noción, se resaltaron dos dimensiones de su relación con el trabajo: atención a su persona, su salud y su bienestar, y apropiación o manejo de su tiempo. 
Cuidar de sí implica conocimiento y pleno desarrollo del potencial de uno. Trabajar de freelance ofrece la oportunidad de atender las necesidades personales, de procurarse bienestar compaginando esfuerzo creativo con entretenimiento y ocio. Cuidar de sí implica tener en sus manos la gestión de su tiempo y estar en o relacionarse con él de un modo personal. El disfrute, que es parte de la atención a su persona, conlleva una relación flexible y libre con el tiempo. Uno cuida de sí al trabajar de freelance explotando todos sus recursos creativos e intelectuales y teniendo proyectos personales. Esto conduce a que día con día uno vaya descubriendo y desarrollando nuevas potencialidades personales.

La apuesta por la autonomía y las prácticas de cuidado de sí corresponden a las primeras dos necesidades básicas que, según la TAD, motivan las acciones de los seres humanos: ser freelance respondería a la disposición profunda hacia la autonomía y la competencia, cuya materialización conduciría a un mayor bienestar de los individuos.

Está fuera del alcance de la presente investigación aquilatar a cabalidad el nivel de bienestar al que llegan, sólo se afirma que los sujetos entrevistados se consideran más satisfechos con su vida como freelances de lo que lo fueron o lo hubieran sido como asalariados. Es así, no obstante las tensiones que generan los altibajos en volumen de trabajo $\mathrm{y}$ de ingresos y el poco reconocimiento que a veces recibe su trabajo de parte de algunos clientes.

Adorno, T. (1987). Minima moralia. Reflexiones desde la vida Bibliografía dañada. Madrid: Taurus.

Alonso, L., y Callejo, J. (1999). "El análisis del discurso: del posmodernismo a las razones prácticas". Revista Española de Investigaciones Sociológicas, (88), 37-73.

Beaucage, A., y Bellemare, G. (2007). "La diversité du succès des travailleurs autonomes". Recherches sociographiques, (2), II-36. 
Bibliografía
Benz, M. y Frey, B. (2004). "Being independent raises happiness at work". Swedish Economic Policy Review, (I I), 95-134.

(2008). "Being independent is a great thing: subjective evaluations of self-employment and hierarchy". Economica, (75), 362-383.

Bologna, S. (2006). Crisis de la clase media y posfordismo. Madrid: Akal.

Buscatto, M. (2004). "De la vocation artistique au travail musical: tensions, compromis et ambivalences chez les musiciens de jazz". Sogiologie de l'art, 5(3), 35-56.

Coulangeon, P. (2004). " $L$ 'expérience de la précatiré dans les professions artistiques. Le cas des musiciens interprètes". Sogiologie de l'art, 5(3), 77-I I 0.

Deci, E., y Ryan, R. (2000). 'The 'what' and 'why' of goal pursuits: human needs and the self-determination of behavior". Psychological Inquiry, I I (2), 227-268.

- y Vansteenkiste, M. (2004). "Self-Determination Theory and basic need satisfaction: understanding human development in positive psychology". Ricerche di Psicologia, 27(I), 23-40.

De la Garza, E. (200I). "El futuro del trabajo-el trabajo del futuro", en E. De la Garza, y J. C. Nefta (comps.), El trabajo del futuro. El futuro del trabajo (pp. I I-3I). Buenos Aires: CLACSO.

Elias, N. (20I0). Sobre el tiempo. México: Fondo de Cultura Económica.

Facebook (08 de septiembre de 20I5). "Mundo Godínez" (información en grupo de red social). Recuperado de: https://www.facebook.com/MundoGod\%C3\%ADnez-2633 I3930476029/timeline/

Frey, B., Benz, M., y Stutzer, A. (2004). "Introducing procedural utility: Not only what, but also how matters". Journal of Institutional and Theoretical Economics, I60(3), 37740I. Recuperado de: www.bsfrey.ch/articles/406_04.pdf 
Gerber, V., y Pinochet, C. (2012). "La era de la colaboración. Bibliografía Mapa abreviado de nuevas estrategias artísticas”, en N. García Canclini, F. Cruces, y M. Urteaga (coords.), Jóvenes, culturas urbanas y redes digitales (pp. 45-63). Madrid: Ariel.

Fleishman, M. (2004). Tu carrera como freelance. Barcelona: Divine Egg.

Foucault, M. (1999). "La ética del cuidado de sí como práctica de la libertad”, en, Estética, ética y hermenéutica (pp. 393- 4I5). Barcelona: Paidós.

(200I). L'Hermeneutique du sujet. Cours au Collège de France, I98I-1982. París: Haute Études/Gallimard/Seuil. Los Godínez (20I4). "Godinean Rhapsody (Yo no soy Godínez)”, en, El lado oscuro de la oficina (grabación audiovisual, disco compacto). México: Casete.

Machado, J. (2007). Chollos, chapuzas, changas. Jóvenes, trabajo precario y futuro. Barcelona: Anthropos/UAM.

Marzano, M. (2008). "Nouvelles formes d'exploitation". Cités, (35), III-122.

(20II). Programados para triunfar. Nuevo capitalismo, gestión empresarial y vida privada. México: Tusquets.

Mayer, U. (2004). "Whose lives? How history, society, and institutions define and shape life courses". Research in human development, I(3), I6I-I87.

Médor, D. (2014a). Entrevista personal realizada a Karim. Guadalajara, Jalisco, México.

(20l4b). Entrevista personal realizada a Mario. Guadalajara, Jalisco, México. (20I4c). Entrevista personal realizada a Marú. Guadalajara, Jalisco, México.

(20|4d). Entrevista personal realizada a Selestina. Guadalajara, Jalisco, México. (20l4e). Entrevista personal realizada a Susana. Guadalajara, Jalisco, México. 

(20I4f). Entrevista personal realizada a Erika. Guadalajara, Jalisco, México.

(20I4g). Entrevista personal realizada a Julieta. Guadalajara, Jalisco, México. (20I4h). Entrevista personal realizada a Emmanuel. Guadalajara, Jalisco, México.

- (20I4i). Entrevista personal realizada a Gilberto. Guadalajara, Jalisco, México.

(20I5a). Entrevista personal realizada a Julio. Guadalajara, Jalisco, México.

(20I5b). Entrevista personal realizada a María. Guadalajara, Jalisco, México.

(20I5c). Entrevista personal realizada a Angel. Guadalajara, Jalisco, México.

- (20I5d). Entrevista personal realizada a Margarita. Guadalajara, Jalisco, México.

(20I5e). Entrevista personal realizada a Itzel. Guadalajara, Jalisco, México.

Menger, P. (199I). "Le marché du travail artistique et la socialisation du risque. Le cas des arts du spectacle". Revue Française de Sociologie, (32), 6I-47.

- (0I de julio de 2009). "La création comme un travail. Qu'est-ce que la sociologie de l'art II”. La vie des idées. Recuperado de: www.laviedesidees.fr/La-creationcomme-un-travail.html

- (20I4). La différence, la concurrence et la disproportion. Sociologie du travail créateur (lección inaugural pronunciada el 9 de enero de 2014). París: Collége de France. Recuperado de http://books.openedition.org/cdf/36/4 Nietzsche, F. (200I). La gaya ciencia. Madrid: AKAL.

Pinto, J. (20I5). Manual del godínez. Guía ilustrada para sobrevivir en la oficina. México: Aguilar.

Ruiz, J. (2009). "Análisis sociológico del discurso: métodos y lógicas”. Forum: Qualitative Social Research, 10(2). Recuperado de: http://www.qualitative-research.net/ 
Ryan, R., y Deci, E. (2000). "The darker and brighter sides of Bibliografía human existence: basic psychological needs as a unifying concept". Psychological Inquiry, I I (4), 319-338.

Sánchez-Escuer, S. (20I3). Apuntes de una oveja freelancera. México: Planeta.

Steiner, L., y Schneider, L. (2012). The Happy Artist?: An Empirical Application of the Work-Preference Model. Berlín: German Institute for Economic Research, SOEP Papers. Recuperado de: www.diw.de/sixcms/detail. php?id=392828

Thoemmes, J., Kanzari, R., y Escarboutel, M. (20I I). "Temporalités des cadres et malaise au travail”. Interventions Economiques. Papers in Political Economy, (43). Recuperado de: http://interventionseconomiques.revues. org/ $|40|$

Urteaga, M. (20I2). "De jóvenes contemporáneos: Trendys, emprendedores y empresarios culturales", en N. García Canclini, F. Cruces, y M. Urteaga (coords.), Jóvenes, culturas urbanas y redes digitales (pp. 25-44). Madrid: Ariel.

Yvon, F., y Clot, Y. (200I). "Le travail en moins. Une approche psychologique de l'activité”. Cités, 4(8), 63-73. 